\title{
DIMENSI PARTISI GRAF LOBSTER
}

\author{
MUTHIA MUHANA, DES WELYYANTI, NARWEN \\ Program Studi S1 Matematika, \\ Fakultas Matematika dan Ilmu Pengetahuan Alam, Universitas Andalas, \\ Kampus UNAND Limau Manis Padang, Indonesia. \\ email : muthiamuhana120997@gmail.com
}

Diterima 9 Maret 2019 Direvisi 7 April 2019 Dipublikasikan 7 Mei 2019

\begin{abstract}
Abstrak. Misalkan terdapat $k$ partisi dengan himpunan terurut $S=\left\{S_{1}, S_{2}, \cdots, S_{k}\right\}$ dari himpunan titik $V(G)$ pada graf terhubung $G=(V, E)$, representasi partisi $v \in V$ terhadap $S$ adalah koordinat $r(v \mid S)$ dengan:

$$
r(v \mid S)=\left(d\left(v, S_{1}\right), d\left(v, S_{2}\right), \cdots, d\left(v, S_{k}\right)\right),
$$

untuk $d\left(v, S_{i}\right)$ menyatakan jarak antara titik $v$ dengan himpunan $S_{i}$ dimana $i=[1, k]$. Partisi $S$ dari $V(G)$ disebut resolving partition dari $G$ jika $\forall v \in V(G)$ memiliki representasi partisi yang berbeda untuk setiap pasangan terurut dari $u, v \in V$ maka $r(u \mid S) \neq r(v \mid S)$. Resolving partition dengan kardinalitas minimum dari $V(G)$ disebut dimensi partisi dari $G$, dinotasikan dengan $p d(G)$. Pada tulisan ini akan dibahas tentang penentuan dimensi partisi untuk Graf Lobster.
\end{abstract}

Kata Kunci: Partisi, Resolving Partition, Dimensi Partisi, Graf Lobster

\section{Pendahuluan}

Dimensi Partisi dari suatu graf merupakan salah satu perkembangan ilmu dalam konsep teori graf yang sedang berkembang saat ini. Penemuan tentang dimensi partisi suatu graf sangat menguntungkan untuk perkembangan ilmu pengetahuan dan teknologi serta memiliki banyak manfaat dalam memecahkan berbagai masalah. Graf Lobster secara umum adalah suatu graf yang diperoleh dari Graf Lintasan dengan menambahkan sejumlah titik pada setiap titik yang ada pada Graf Lintasan tersebut, lalu menambahkan sejumlah titik lagi pada titik yang berderajat satu [2].

Misalkan terdapat $k$ partisi dengan himpunan terurut $S=\left\{S_{1}, S_{2}, \cdots, S_{k}\right\}$ dari himpunan titik $V(G)$ pada graf terhubung $G=(V, E)$, representasi partisi $v \in V$ terhadap $S$ adalah koordinat $r(v \mid S)$ dengan:

$$
r(v \mid S)=\left(d\left(v, S_{1}\right), d\left(v, S_{2}\right), \cdots, d\left(v, S_{k}\right)\right),
$$

untuk $d\left(v, S_{i}\right)$ menyatakan jarak antara titik $v$ dengan himpunan $S_{i}$ dimana $i=$ $[1, k]$. Partisi $S$ dari $V(G)$ disebut resolving partition dari $G$ jika $\forall v \in V(G)$ memiliki representasi partisi yang berbeda untuk setiap pasangan terurut dari $u, v \in V$ maka $r(u \mid S) \neq r(v \mid S)$. Resolving partition dengan kardinalitas minimum dari $V(G)$ disebut dimensi partisi dari $G$, dinotasikan dengan $p d(G)[1]$. 
Chartrand dkk. (2000) telah memberikan lema dan teorema dasar dimensi partisi suatu graf, seperti berikut:

Lema 1.1. [1] Misalkan $G$ suatu graf terhubung tak trivial. Misalkan suatu partisi dari $G$ dan $u, v \in V(G)$. Jika $d(u, w)=d(v, w) ; \forall w \in V(G)-\{u, v\}$, maka u dan $v$ berada dalam kelas partisi yang berbeda pada $S$.

Teorema 1.2. [1] Misalkan $G$ adalah Graf Terhubung dengan orde $n \geqslant 2$, maka $p d(G)=2$ jika dan hanya jika $G \cong P_{n}$.

Teorema 1.3. [1] Misalkan $G$ adalah Graf Terhubung dengan $G \cong K_{1, n}$ untuk $n \geq 3, \operatorname{maka} \operatorname{pd}(G)=n$

\section{Dimensi Partisi Graf Lobster}

Pada bab ini akan dibahas tentang dimensi partisi untuk Graf Lobster yang dibatasi untuk Graf Lobster teratur, dinotasikan sebagai $L_{n(p, q)}$ untuk $n \geq 2, p=1$ dan $n, p, q \in N$.

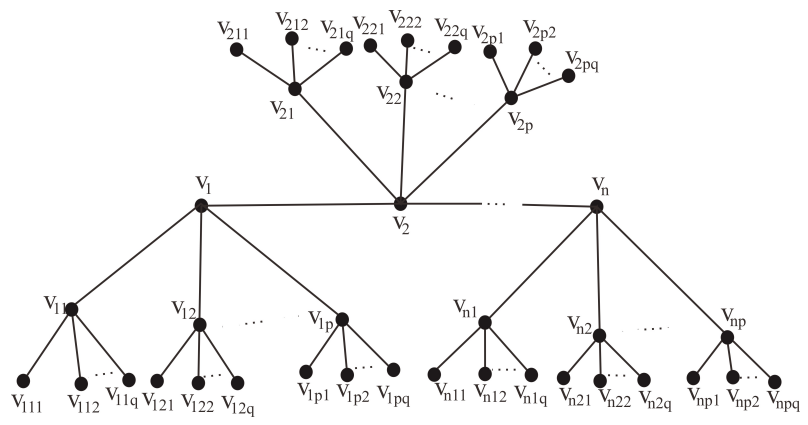

Gambar 1. Graf Lobster teratur $L_{n(p, q)}$

Teorema 2.1. Jika terdapat Graf Lobster $L_{n(p, q)}$, dengan $n \geq 2, p=1$ dan $n, p, q \in$ $N$ maka:

$$
p d\left(L_{n(p, q)}\right)=\left\{\begin{array}{l}
2, \text { untuk } n=2 ; q=1 \\
3, \text { untuk } n \geq 3 ; q=1
\end{array}\right.
$$

Bukti. Misalkan terdapat Graf Lobster $L_{n(p, q)}$ dengan $n \geq 2, p=1$ dan $n, p, q \in N$. Akan ditunjukkan bahwa untuk $n=2$ dan $q=1$, maka $p d\left(L_{n(p, q)}\right)=2$. Karena $L_{2(1,1)} \cong P_{6}$, berdasarkan Teorema 1.2 , maka $p d\left(L_{2(1,1)}\right)=2$.

Akan ditunjukkan bahwa untuk $n \geq 3$ dan $q=1$, maka $p d\left(L_{n(p, q)}\right)=3$.

(1) Akan ditunjukkan $p d(H) \geq 3$. Karena graf yang memiliki $p d(H)=2$ hanyalah graf lintasan, maka $p d\left(L_{n(1,1)}\right) \geq 3$. 


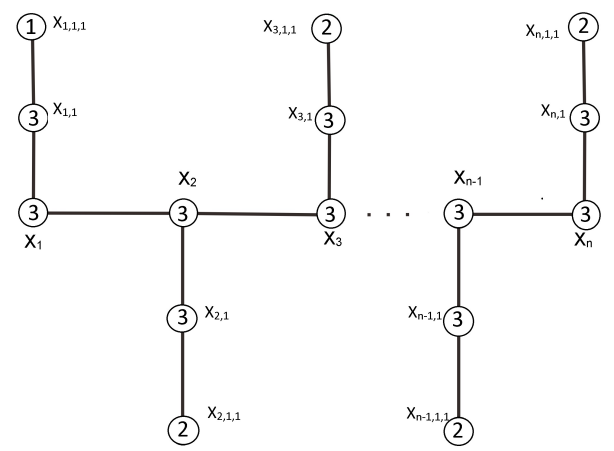

Gambar 2. Graf Lobster $L_{n(1,1)}$

(2) Akan ditunjukkan $p d(H) \leq 3$. Pilih partisi sebagai berikut:

$$
\begin{aligned}
S & =\left\{S_{1}, S_{2}, S_{3}\right\}, \text { dimana: } \\
S_{1} & =\left\{x_{1,1,1}\right\}, \\
S_{2} & =\left\{x_{i, 1,1} \mid i=2,3, \cdots n\right\}, \\
S_{3} & =V\left(L_{n(p, q)}\right) \backslash\left\{S_{1}, S_{2}\right\} .
\end{aligned}
$$

Dengan pemilihan $S$ seperti di atas, maka diperoleh representasi sebagai berikut.

(a) Untuk titik yang berada pada $S_{1}$, bentuk representasinya adalah:

$$
r\left(x_{1,1,1} \mid S\right)=\left(d\left(x_{1,1,1}, S_{1}\right), d\left(x_{1,1,1}, S_{2}\right), d\left(x_{1,1,1}, S_{3}\right)\right)=(0,5,1) .
$$

(b) Untuk titik yang berada pada $S_{2}$, bentuk representasinya adalah:

$$
r\left(x_{i, 1,1} \mid S\right)=\left(d\left(x_{i, 1,1}, S_{1}\right), d\left(x_{i, 1,1}, S_{2}\right), d\left(x_{i, 1,1}, S_{3}\right)\right)=(i+3,0,1) ; i=2,3, \cdots, n .
$$

(c) Untuk titik yang berada pada $S_{3}$, bentuk representasinya adalah:

$$
\begin{aligned}
r\left(x_{1} \mid S\right) & =\left(d\left(x_{1}, S_{1}\right), d\left(x_{1}, S_{2}\right), d\left(x_{1}, S_{3}\right)\right)=(2,3,0), \\
r\left(x_{i} \mid S\right) & =\left(d\left(x_{i}, S_{1}\right), d\left(x_{i}, S_{2}\right), d\left(x_{i}, S_{3}\right)\right)=(i+1,2,0) ; i=2,3, \cdots, n, \\
r\left(x_{1,1} \mid S\right) & =\left(d\left(x_{1,1}, S_{1}\right), d\left(x_{1,1}, S_{2}\right), d\left(x_{1,1}, S_{3}\right)\right)=(1,4,0), \\
r\left(x_{i, 1} \mid S\right) & =\left(d\left(x_{i, 1}, S_{1}\right), d\left(x_{i, 1}, S_{2}\right), d\left(x_{i, 1}, S_{3}\right)\right)=(i+2,1,0) ; i=2,3, \cdots, n .
\end{aligned}
$$

Karena representasi setiap titik terhadap $S$ berbeda, maka diperoleh $p d\left(L_{n(1,1)} ; n \geq 4\right) \leq 3$.

Berdasarkan (i) dan (ii) diperoleh bahwa $p d\left(L_{n(1,1)}\right)=3$.

\section{Kesimpulan}

Pada penelitian ini diperoleh bahwa:

$$
p d\left(L_{n(p, q)}\right)=\left\{\begin{array}{l}
2, \text { untuk } n=2 ; q=1 \\
3, \text { untuk } n \geq 3 ; q=1
\end{array}\right.
$$


218 Muthia Muhana dkk

\section{Ucapan Terima kasih}

Terima kasih kepada Bapak Dr. Admi Nazra, M.Si., M.Sc., Ibu Dr. Lyra Yulianti dan Ibu Dr. Susila Bahri selaku penguji atas kritik dan sarannya.

\section{Daftar Pustaka}

[1] Chartrand, G., Salehi, E., dan Zhang, P.2000. The Partition Dimension of a Graph. Aequationes Mathematicae 59: 45 - 54

[2] Khan. N. Pal, dan Pal. M. 2009. Edge Colouring of Cactus Graph. AMOAdvanced Modeling and Optimization. $11: 4$ 